\title{
HUBUNGAN JUMLAH KUNNUNGAN WISATAWAN TERHADAP BIAYA - BIAYA OPERASIONAL PADA HOTEL SUNARI
}

\author{
KADEK ARTINI \\ Jurusan Akuntansi Program Diploma III, \\ Universitas Pendidikan Ganesha, SIngaraja \\ Email : Kadeartini07@gmail.com
}

\begin{abstract}
Abstrak
Penelitian ini bertujuan untuk mengetahui hubungan jumlah kunjungan wisatawan terhadap biaya-biaya opearsional pada Hotel Sunari.

Subjek penelitian ini adalah Hotel Sunari yang beralamat di Dusun Banyualit, Desa Kalibukbuk, tepatnya di Jalan Raya Lovina - Kalibukbuk Singaraja Bali, sedangkan objek penelitian adalah Hubungan Jumlah Kunjungan Wisatawan Terhadapbiaya-biaya Operasional pada Hotel Sunari. Teknik pengumpulan data yang digunakan dalam penelitian ini adalah wawancara, dokumentasi, dan studi kepustakaan. Teknik analisis yang digunakan adalah teknik analisis koefesien kolerasi.

Hasil penelitian menunjukan bahwa besarnya hubungan jumlah kunjungan wisatawan terhadap biaya operasional paada Hotel Sunari untuk tahun 2016 sebesar $11,115 \%$, artinya naik turun biaya operasional pada Hotel Sunari yang di keluarkan dipengaruhi $11,115 \%$ jumlah kunjungan wisatawan dan sisanya $88,885 \%$ di pengaruhi oleh factor lainya.
\end{abstract}

Kata-kata kunci: Jumlah kunjungan wisatawan, Biaya operasional.

\begin{abstract}
This study aims to determine the relation of the number of tourist visits to the opearsional costs at Sunari Hotel.

The subject of this research is Sunari Hotel which is located at Dusun Banyualit, Kalibukbuk Village, precisely on Jalan Raya Lovina - Kalibukbuk Singaraja Bali, while the object of research is Relationship Number of Tourist Visits To Operational Costs at Hotel Sunari. Data collection techniques used in this study are interviews, documentation, and literature study. Analysis technique used is correlation coefficient analysis technique.

The result of the research shows that the number of tourist visits to the operational cost of Sunari Hotel for the year 2016 amounted to 11.115\%, it means up and down the operational costs at Sunari Hotel which is influenced $11.115 \%$ the number of tourist visits and the remaining $88.885 \%$ influenced by other factors.
\end{abstract}

Keywords: Number of tourist visits, Operational costs

\section{Pendahuluan}

Indonesia sebagai negara yang berkembang dalam tahap pembagunanya berusaha membangun industri pariwisata, sebagai salah satu cara untuk mencapai neraca perdagangan luar negeri yang berimbang, karena melalui industri ini pemasukan devisa negara dapat bertambah, Kepariwisataan juga memberikan dorongan langsung terhadap kemajuan-kemajuan pembangunan, perbaikan pelabuhan-pelabuhan (laut atau udara), jalan raya, pengangkutan, program kebersihan atau kesehatan dan kelestarian lingkungan yang semuanya memberikan keuntungan dan kesenangan bagi masyarakat dalam lingkungan daerah yang bersangkutan maupun bagi wisatawan pengunjung dari luar.

Kepariwisataan juga memberikan sumbangan terhadap pelaksanaan pembangunan proyek - proyek berbagai sektor negara-negara yang telah berkembang atau maju prekonominya, dimana industri pariwisata merupakan suatu ketahanan di tengah-tengah industri lainya. 
VOL.7, NO. 2, OKTOBER 2018

p-ISSN : 2337-537X

Sektor pariwisata ini juga sektor yang potensial untuk dikembangkan sebagai salah satu sumber pendapatan daerah.Usaha memperbesar pendapatan daerah, maka program pengembangan dan pendayagunaan sumber daya dan potensi pariwisata daerah diharapkan dapat memberikan sumbangan bagi pembangunan ekonomi. Secara luas pariwisata dipandang sebagai kegiatan yang mempunyai multidimensi dari rangkaian suatu proses pembangunan.

Pembangunan sektor pariwisata menyangkut aspek sosial budaya, ekonomi dan politik (Spillane, 2004:14). Hal tersebut sejalan dengan yang tercantum dalam UndangUndang Nomor 10 tahun 2009 Tentang Kepariwisataan yang menyatakan bahwa Penyelenggaraan kepariwisataan ditujukan untuk meningkatkan pendapatan nasional, dalam rangka meningkatkan kesejahteraan dan kemakmuran rakyat, memperluas dan memeratakan kesempatan pengusaha dan lapangan kerja, mendorong pembangunan daerah, memperkenalkan dan mendayagunakan obyek dan daya tarik wisata di Indonesia serta memupuk rasa cinta tanah air dan mempererat persahabatan antar bangsa.

Kondisi pariwisata Bali yang terpuruk sebagai akibat terjadinya tragedi bom Bali 1 dan 2, maka para pengusaha restoran, agen perjalan (travel), dan hotel khususnya mencari jalan keluar untuk tetap eksis. Pariwisata sangat besar pengaruhnya dalah kehidupan ekonomi. Lesu tidaknya pasar tergantung pada keadaan pariwisatanya, karena sebagaian besar masyarakat di Bali berprofesi di bidang pariwisata seperti pemandu wisata maupun berkerja di hotel dan restoran. Banyak dampak yang di timbulkan dari keberadaan pariwisata salah satunya terbukanya lapangan pekerjaan. Dengan kunjungan wisatawan-wisatawan tersebut para pelaku pasar diatas memperoleh pengasilan yang dapat memenuhi kebutuhan hidup mereka.

Akomondasi merupaakn faktor yang sangat penting, ini merupakan "rumah sementara"bagi wisatawan sejauh atau sepanjang perjalanan membutuhkan serta mengharapkan kenyamanan, kebersihan yang baik, dan pelayanan yang baik. Akomondasi dalam aliran industri pariwisata lazimnya berbentuk hotel, motel, bungalow, penginapan, losmen, pondok, homestay dan lain-lain. Akomondasi ini merupakan komponen penting di bidang pariwisata, disinilah nantinya wisatawan dapat beristirahat makan dan minum, serta ada fasilitas-fasilitas seperti kolam renang, pusat olah raga, hiburan, salon, dan spa.

Hotel Sunari salah satu yang menyediakan sarana-sarana tersebut yang beralamat di Jalan Raya Lovina, Ds.Kalibukbuk,Singaraja,Bali, lokasinya yang trategis dekat dengan pantai lovina dengan keindahan ombak dan matahari terbenamya sangat cocok bagi wisatawan yang ingin berkunjung dengan menikmati suasana pantai, hotel ini juga memiliki fasilitas meliputi pusat bisnis,bar, restoran, dan memiliki kolam renang, outdor serta kamar yang luas dengan fasilitas yang lengkap seperti Ac, balkon pribadi, mini bar, dan tv kabel. Para wisatawan juga bisa menikmati fasilitas pijat, perawatan tubuh, dan hot tub di Balines Spa bergaya tradisional serta tersedia fasilitas internet gratis diarea umum.

Semua itu penting menunjang agar kemajuan pariwisata terus tetap lancar, kita harus menyadari juga untuk menegakan industri pariwisata maka politik pemerintah langsung maupun tidak langsung mempengaruhi kunjungan wisatawan yaitu situasi ekonomi, politik, dan keamanan dalam negri stabil adalah merupakan syarat utama. Terkadang akibat ketidak serasian situasi masyarakat multi etnis Indonesia dihadapkan pada hal-hal yang menimbulkan salah paham sehingga bentrokan disana sini tidak dihindarkan seakan-akan diseluruh pelosok Indonesia "tidak aman". Perintah bersama-sama komponen bangsa dan seluruh masyarakat berupaya menanamkan pemahaman bahwa situasi aman dan damai dapat mengantar pariwisata keposisi yang sebenarnya sebagai industri dalam wujud invisible exsport( ekspor tidak nyata) berkat beragam destinasi daya tarik wisata produk-produk paket wisata dan jasa pelayanan wisata yang ramah, Indonesia harus mampu membangaun indutri pariwisatanya intensif dan dapat bersaing dengan pariwisata dunia. 
VOL.7, NO. 2, OKTOBER 2018

p-ISSN : 2337-537X

Berdasarkan uraian dan memaparkan latar blakang di atas peneliti meneliti mengenai permasalahan hubungan kunjungan wisatawan terhadap biaya-biaya operasional pada Hotel Sunari.

\section{Metode Penelitian}

Penelitian ini mengunakan data dengan analisis koefisien korelasi dengancara menguraikan dan memaparkan secara umum mengenai biayaa-biaya pada Hotel Sunari untuk dievaluasi. Lokasi penelitian ini dilakukan pada Hotel Sunari dan melibatkan variabelvariabel jumlah kunjungan wisatawan dan biaya operasional pada Hotel Sunari. Jenis data yang digunakan adalah data kuantitatif yang berupa angka-angka serta perhitungan, sedangkan mengenai sumber data digunakan data skunder yaitu data-data yang penulis dapat langsung dari Hotel Sunari. Serta metode yang digunakan untuk mengumpulkan data yaitu wawancara, dokumentasi, serta studi kepustakaan, sehingga dari perumusan tersebut dapat diperoleh hasil akhir dan dapat ditarik suatu kesimpulan.

Adapun yang menjadi subjek dalam penelitian ini adalah Hotel Sunari, sedangkan yang menjadi objek penelitian ini adalah Hubungan Jumlah Kunjungan Wisatawan Terhadap Biaya-Biaya Operasional Pada Hotel Sunari.

Jenis data dan sumber data yang digunakan dalam penelitian ini yakni,data kuantitatif yang berupa data angka-angka serta hitungan. Sesuai dengan penelitian ini data kuantitatif yang dimgsud adalah jumlah kunjungan wisatawan dan biaya oprasional, dan sumber datayang digunakan adalah data skunder yaitu data-data yang di peroleh dari dokumen kumpulan biaya-biaya oprasional dan jumlah kunjungan wisatawan.

Metode pengumpulan data yang digunakan dalam penelitian ini adalahmetode wawancara yaitu pengumpulan data dengan melakukan interaksi langsung/tanya jawab dengan pinpinan atau pihak- pihak yang ada hubunganya dengan data yang diperlukan mengenai pengaruh jumlah wisatawan terhadap biayaoperasional pada Hotel Sunari, dokumentasi yaitu suatu teknik pengumpulan dan pencatatan data dengan cara mengumpulkan bukti-bukti dan keterangan yang berupa arsip dan surat yang ditunjukan untuk mendapatkan data jumlah kunjungan wisatawan, malaui kasir, atau cost control Hotel Sunari, dan studi kepustakan adalah cara untuk menjelaskan data dengan cara membaca berbagai literatur yang ada kaitanya dengan penelitian dan sebagai usaha kajian dalam mengambil kesimpulan.

Analisis data yang digunakan dalam penelitian ini adalah analisis koefisien kolerasi dengan cara menguraikan dan memaparkan secara kuantitatif mengenai biaya-biaya pada Hotel Sunari untuk dievaluasi, sehingga diperoleh satu kesimpulan yang bersifat umum. Untuk perumusan masalah digunakan rumus menurut (Husein Umar). Dalam statistik kolerasi hubungan antara dua variabel atau lebih. Hubuangan anatara variabel tersebut jika dilihat dari segi arahnya dapat dibedakan menjadi dua macam, yaitu yang sifatnya satu arah dan berlawanan arah, hubunganya yang sifatnyan searah dinamakan kolerasi positif, sedangkan sifatnya yang berlawanan arah dinamakan kolerasi negative. Dua variabel yang hendak diselidiki hubunganya itu biasanya diberi kode $x$ dan $y$. Untuk mengetahui apakah ada hubungan atau tidak antara jumlah kunjuangan dengan biaya oprasional, maka variable jumlah kunjuangan di beri kode $\mathrm{x}$, sedangkan variabel biaya operasional di beri kode $\mathrm{y}$. Untuk mengukur hubungan jumlah kunjungan wisatawan dengan biaya operasional hotel berdasarkan sekumpulan data digunakan rumus koefisien kolerasi:

$$
r \frac{=n\left(\sum x y\right)-\left(\sum x \sum y\right)}{\sqrt{\left[n \sum \bar{x}^{2}-\left(\sum x\right)^{2}\right]\left[n \sum y^{2}-\left(\sum y\right)^{2}\right]}}
$$

\section{Keterangan:}

$\mathrm{r} \quad=$ angka indeks kolerasi antara variabel $\mathrm{x}$ dan variabel $\mathrm{y}$. 
VOL.7, NO. 2, OKTOBER 2018

p-ISSN : 2337-537X

$\sum_{x y} \quad=$ jumlah hasil kali antara skor variabel $\mathrm{x}$ danskor variabel $\mathrm{y}$.

$\sum x \quad=$ jumlah skor variabel $x$.

$\sum \mathrm{y}=$ jumlah skor variabel $\mathrm{y}$.

$\sum \times 2=$ jumlah skor kuadrat $\mathrm{x}$.

$\sum_{y 2}=$ jumlah skor kuadrat $y$.

Untuk jumlah wisatawan merupaakan variabel bebas $(\mathrm{x})$, sedangkan untuk biaya operasional merupakan variabel terikat $(\mathrm{y})$.

Untuk dapat memberikan penafsiran terhadap koefisien korelasi yang ditentukan tersebut besar atau kecil pengaruhnya, maka dapat berpedoman pada ketentuan yang tertera pada tabel sebagai berikut Pedoman Interpretasi Koefisien Korelasi

Tabel 1.

Interval Koefisien

\begin{tabular}{ll}
\hline Interval Koefisien & Tingkat Hubungan \\
\hline $0,00-0,199$ & Sangat Rendah \\
$0,20-0,399$ & Rendah \\
$0,40-0,599$ & Sedang \\
$0,60-0,799$ & Kuat \\
$0,80-1,000$ & Sangat Kuat \\
\hline \multicolumn{2}{c}{ Sumber : Sugiyono (2002:183) }
\end{tabular}

Kemudian dicari tingkat hubungan antara variable $\mathrm{x}$ dan variable $\mathrm{y}$, dengan rumus koefesien determinasi. Koefisien determinasi digunakan untuk menunjukan seberapa besar pengaruh antara kedua variabel yang diteliti, maka dihitung koefisien detrminasi (Kd) dengan asumsi faktor-faktor lain diluar variabel dianggap konstan/tetap (cateris paribus). Rumus koefisien determinasi (Kd) yaitu $\quad: \quad K d=r^{2} \times 100 \%$

Keterangan : $\quad \mathrm{Kd}=$ Koefisien Determinasi

Dimana apabila:

$$
\mathrm{R}=\text { Koefisien korelasi }
$$

$\mathrm{Kd}=0$, Berarti pengaruh variabel $\mathrm{x}$ terhadap variabel $\mathrm{y}$, lemah.

$K d=1$, Berarti pengaruh variabel $x$ terhadap variabel $y$, kuat

Pengaruh tinggi rendahnya koefisien determinasi tersebut digunakan pedoman yang dikemukakan oleh Guilford yang dikutip oleh Supranto (2001:227) adalah sebagai berikut :

Pedoman Interpretasi Koefisien Determinasi

$$
\begin{array}{ll}
\text { Pernyataan } & \text { Keterangan } \\
>4 \% & \begin{array}{l}
\text { Pengaruh Rendah } \\
\text { Sekali }
\end{array} \\
5 \%-16 \% & \begin{array}{l}
\text { Pengaruh Rendah } \\
\text { Tapi Pasti }
\end{array} \\
17 \%-49 \% & \begin{array}{l}
\text { Pengaruh Cukup } \\
\text { Berarti }
\end{array} \\
50 \%-81 \% & \begin{array}{l}
\text { Pengaruh Tinggi } \\
\text { atau Kuat }
\end{array}
\end{array}
$$


VOL.7, NO. 2, OKTOBER 2018

p-ISSN : 2337-537X

$$
\begin{array}{ll}
>80 \% & \text { Pangaruh Tinggi } \\
\text { Sekali }
\end{array}
$$

Sumber : Supranto (2001:227)

\section{Hasil dan Pembahasan}

Dari pembahasan di atas, terlepas dari sejarah dan struktur organisasi dan wewenang pada Hotel Sunari maka dapat dijelaskan bahwa biaya yang dikeluarkan dibulan januari sesuai dengan jumlah kunjungan wisatawan pada akhir tahun yang cukup banyak. Pada bulan februari terjadi penurunan biaya sekitar $31,6 \%$ dikarena terjadi pennurunan jumlah kunjungan wisatawan. Biaya-biaya yang harus dikelurkan hotel mengalami penurunan yang semula pada bulan januari sebesar Rp. 316.048.205 dengan jumlah kunjungan wisatawan 1070 menjadi Rp.215,869.032 pada bulan februari dengan jumlah kunjungan wisatawan 959, maka selisih biaya dari bulan januari ke bulan februari adalah Rp.100.179.182 serta jumlah kunjungan wisatawan yang berkurang mencapai 111 ini berarti jumlah kunjungan wisatawan berpengaruh terhadap biaya-biayaoperasional yang di keluarkan pada Hotel Sunari. Sehingga jika terjadi penurunan kunjungan wisatawan maka biaya operasional pada hotel pun ikut berkurang.

Keadaan jumlah kunjungan wisatawan pada bulan maret kembali mengalami peningkatan dan terjadi penurunan kembali pada bulan april dan mei, mendekati bulan juni terjadi peningkatan biaya dan jumlah kunjungan dari bulan sebelumnya, peningkatan berlangsung sampai bulan agustus di sebabkan karna pada bulan-bulan ini merupakan bulan liburan. Selanjutnya dari bulan September sampai November kembali mengalmi penurunan jumlah kunjungan wisatawan hingga bulan Desember mengalami peningkatan kembali sampai liburan akhir tahun.

Sedangkan untuk mengetahui hubungan jumlah kunjungan wisatawan terhadap biaya-biaya operasional pada Hotel sunari digunakan rumus perhitungan koefesion kolerasi dan untuk mengetahui seberapa besar pengaruh jumlah kunjungan wisatawan terhadaap biaya operasional digunakan rumus koefesion determinasi. Dengan menjabarkan rumusrumus tersebut dapat diperoleh hasil sebesar 0,334 dari hasil perhitungan koefesion kolerasinya, yang artinya hubungsn antara jumlah kunjungan wisatawan dengan biaya operasional yang dikeluarkan menunjukan arah yang positif dengan indicator hubungan kedua variabel termasuk rendah,ini dapat diartikan jika jumlah kunjungan wisatawan meningkat maka biaya operasional pun juga ikut meningkat namun dalam indicator yang rendah.

Selanjutnya perhitungan koefesion determinasi di peroleh hasil $11,115 \%$ ini berarti naik turunya biaya operasional yang dikelurkan sebesar $11,115 \%$ di pengaruhi oleh jumlah kunjungan wisatawan dengan indkator pengaruh yang rendah namun pasti, dan sisanya sebesar $88,55 \%$ di pengaruhi oleh factor lain,. Dilakukannya penelitian ini untuk mengetahui hubungan jumlah kunjungan wisatawan terhadap biaya operasional, maka masalah dan tujuan dari penelitian ini telah dirumuskan sampai bisa diketahui atau tercapai.

\section{Simpulan dan Saran}

Berdasarkan hasil penelitian dan pembahasan yang telah diuraikan tentang hubungan jumlah kunjungan wisatawan terhadap biaya-biaya operasional pada Hotel Sunari dapat ditaraik kesimpulan bahawa dari perhitungan didapatkan hasil $r_{x y}=0.334, r^{2}=11,115$ $\%$ maka 'dapatditarik kesimpulan bahwa anatara jumlah kunjungan wisatawan terhadap biaya-biaya operasional pada Hotel Sunari terdapat kolerasi yang menunjukan keaarah yang positif, artinya jika jumlah kunjungan meningkat maka jumlah biaya operasional pun ikut meningkat namun dengan indicator hubungan yang rendah. Selanjutnya seberapa besar hubungan hubungan kunjungan wisatawan dengan biaya operasional dengan mengunakan rumus koefesion determinasi diperoleh hasil $11.115 \%$ ini diartikan bahwa naik turunya 
VOL.7, NO. 2, OKTOBER 2018

p-ISSN : 2337-537X

biaya-biaya operasional pada Hotel Sunari dipengaruhi sebesar $11,115 \%$ oleh jumlah kunjungan wisatawan dengan indikator yang rendah namun pasti dan sisanya di penagruhi oleh faktor yang lain.

Berdasarkan snalisis dan simpulan diatas, maka saran yang dapat diberikan sebagai bahan pertimbangan bagi pihak Hotel Sunari dalam meningkatkan jumlah kunjungan wisatawan,ada beberapa cara yang dapat dilakukan berupa memberikat potongan harga, memberikan paket-paket khusus pada hari libur,dan juga pada saat ulang tahun hotel untuk meningkatkan ninat para wisatawan untuk berlibur, dan Hotel Sunari mampu meningkatkan kuantitas daan kualitas pelayanan hotel di masing-masing depaertemen agar mempertahankan citra yang baik di mata wisatawan.

\section{DAFTAR PUSTAKA}

Maher, 1997. Akuntansi Biaya Jilid1.Jakarta : Erlangga

Mulyadi, 1990. Akuntansi Biaya Edisi 4. Yogyakarta : BPFE.

Mulyadi, 1993. Akuntansi Biaya Edisi 5. Yogyakarta : STIE

Mulyadi,1989. Sistem Akuntansi Edisi ke 2. Yogyakarta : Sekolah Tinggi IImu Ekonomi YKPN.

Nata, Wirawan, 2001. (Statistik Deskristif). : Keraras Emas

Pendit, Nyoman S, 2003. IImuu Pariwisata Cetakan Ketujuh.Jakarta : PT.

Pradnyan Paramita, 2004. Pegantar pariwisata,. Sekolah : Pariwisata Bali.

Rahtoem,2014. Deskripsi Tentang IImu Perhotelan.(online)

Http://rah-toem.blongspot.com/2014/07/deskripsi-tentang-indutstri-perhotelan.html?m=1, diakses tanggal 8 Juni 2017)

Sujana, 2001. Metode Statistika. Bandung : PT. Tarsito Bandung.

Sulistyono, 1990. Manajemen Penyelengaraan Hotel. Bandung : CV. Alfabet Bandung.

Supriono, 1983. Akuntasi Biaya. Yogyakarata : Penerbit BPFE

Sutrisno, Hadi. 1983. Metodologi Reserch Jilid 3. Yogyakarta : ANDI Yogyakarta

Spillane, 2014. Pengaruh Sektor Pariwisata Terhadap Peruumbuthan Ekonomi (online)

http://asyharnotes.blogspot.co.id/2014/pengartuh-sektor-pariwisata-terhadap.html?m=1, diakses tanggal 1 juni 2017)

Sutgiono,2002. Metode Penelitian (online)

http://digilib.unpas.ac.id/files/disk1/153/ibptupaspp-gdl-rimaamelia-2607-3-bsbii.pdf (diakses tanggal 8 juni 2017)

Sutpranto,2001.Objek dan Metode Penelitian.(online)

http://elib.unikom.ac.id/dowload.php?id=93833 diakses tanggal 5 juni 2017) 